\title{
Chapter 9 \\ Enhancing Transportation Service Experience in Developing Countries: A Post Pandemic Perspective
}

\section{Emmanuel Mogaji, Ibrahim Ayoade Adekunle, and Nguyen Phong Nguyen}

\begin{abstract}
The impact of COVID-19 on human activities has been immense, and the consequences are still unfolding. The arrival of COVID-19 has changed the provision and delivery of transportation services. This chapter specifically focuses on the anticipated post-pandemic changing nature of the service and service industries with particular reference to the Nigerian transport industry and its post-pandemic outlook. Nigeria, a developing country with existing underlying economic challenges, weak transportation infrastructures, and a growing population, faces a multitude of challenges adjusting to the 'new normal' post-pandemic. This chapter contributes to the emerging literature on the impact of the pandemic on developing countries; it presents the opportunities and inherent challenges for services providers, service design and service quality and improvement. The study recognises the impact of poor infrastructure on transportation and ardently on transport services provision and service system and process. Managerial implications for government, policymakers and transport services providers were also provided. Transportation service providers also need to redesign and co-create value in their services in recognition of an immediate transition of service processes, effectively communicate and engage with the customer through social media and other platforms and ensuring technology-enabled customer encounters.
\end{abstract}

Keywords COVID-19 $\cdot$ Pandemic $\cdot$ Nigeria $\cdot$ Developing countries • Transportation $\cdot$ Service experience $\cdot$ Service design

\footnotetext{
E. Mogaji (ه)

Department of Marketing, Events and Tourism, University of Greenwich, London, UK e-mail: e.o.mogaji@greenwich.ac.uk

E. Mogaji · N. P. Nguyen

Department of Research Administration and International Relations, University of Economics Ho Chi Minh City, Ho Chi Minh City, Vietnam

e-mail: nguyenphongnguyen@ueh.edu.vn

\section{A. Adekunle}

Department of Economics, Olabisi Onabanjo University, Ago Iwoye, Ogun State, Nigeria e-mail: adekunle_ia@yahoo.com
}

J. Lee and S. H. Han (eds.), The Future of Service Post-COVID-19 Pandemic, Volume 1, 


\subsection{Introduction}

The impact of COVID-19 on human activities has been immense, and the consequences are still unfolding. Its impact on transportation is also well acknowledged, but the dimensions to which COVID-19 affects transportation as a critical service industry remains ambiguous. This paper moves beyond the recognition of the impact on dealing with this image in the "new normal" (post-pandemic). This study specifically focuses on dealing with the impact of this pandemic in developing countries. It is essential to recognise that while the pandemic is threatening every country, developing countries do have their fundamental economic and structural challenges, which make them deal with these impacts on a different level and scale.

This chapter focuses on dealing with the present and long-term impact of COVID19 on transportation services in Nigeria. With a population of over 200 million, Nigeria, a key regional actor in the African continent and an emerging economy with underlying economic challenges that persist as it copes with the pandemic. The country ranks as Africa's largest producer of oil and the sixth-largest oil-producing country in the world, with approximately $90 \%$ of its export earnings being tied to oil (NNPC 2020). Nigeria has 36 states, and Abuja is the Federal Capital Territory.

Nigeria is one of the world's major emerging economies, which includes countries like Brazil, China, Colombia, India, Indonesia, Iran, Mexico, Russia, South Africa, Turkey, and Vietnam. These are countries with large populations, experiencing considerable changes to their urban structure (Pojani and Stead 2017). These developing countries are facing institutional adversity and with underlying economic challenges that persist as it copes with the pandemic (Mogaji 2020). Besides, as remote work is trialled globally and people working from home, reducing travel needs, power supply and internet connections. Moreover, the large informal economy in Nigeria has often ensured people have to travel daily to work, putting much pressure on public transport and other infrastructure.

The road is the most prevalent and extensively used form of transportation (Nwafor and Onya 2019); used in Nigeria. However, the inadequate fleets of public transport vehicles and sparse road networks present significant concerns for the country preCOVID, and worse scenarios are anticipated post-pandemic particularly with the desire of transport stakeholders (commuters, operators and government) to adhere to social distancing directives. Nigeria has been one of the most populated countries around the world. The concern of safety placed in the forefront of transport demands of commuters at the time of this global pandemic, the nation is expected to record significant growth in the number of vehicles on the road, leading to traffic congestion and gridlock as well as the shorter life span of transport infrastructure and increased cost of transport facilities maintenance. Commuters lose up to $75 \%$ of weekly working hours as a result of traffic congestion (Obi 2018). With more vehicles on the road and transportation of human and goods having to be done in a way that ensures strict adherence to social distancing protocols, the average journey time will almost double what it is now and loss of working hours as a result of traffic even made worse. 
In light of the above and coupled with the impact of this pandemic on a global scale, this chapter fills a gap in the understanding of how developing countries can cope with the impact of the pandemic in both short-term and long term. This chapter response to the call for a better understanding of the impact of COVID-19 pandemic on transportation services and how developing nations can deal with the 'new normal'. The chapter is expected to make a theoretical contribution to the study of post-pandemic management and delivery of transportation services, especially in developing countries. Also, it offers practical suggestions for transportation services managers about how to protect transport operators, redesign their infrastructures and services to meet the changing needs of the commuters. Finally, the insights from the chapter should help transport managers, technology developers and government policymakers to make suitable adjustments to the built environment, develop technology to aid service delivery and the integration of other relevant transport technologies.

The rest of this chapter is organised as follows. The next section presents insight into transportation in Nigeria, recognising its unique features and existing challenges. This section is followed by a case study analysis of COVID-19 induced transport service delivery in Lagos, Nigeria. The subsequent section explores measures of enhancing transport service experience in developing countries, citing examples from developed countries and the analysis of the result. It highlights the need for customer engagement, service design and service process. The final section concludes the chapter.

\subsection{Transportation in Nigeria}

There inherent challenges in managing urban transportation in sub-Saharan Africa (SSA) are daunting (Gorham 2017). The urban land-use patterns, transport governance, decision-making, and financing and spatial structure create challenges that present massive difficulty in managing urban transport (Pojani and Stead 2017). The political and socio-economic state of Nigeria shows a distinct characteristic of urban transportation (Gorham 2017).

To contextualise the impact of COVID-19 on transportation in Nigeria, it is essential to recognise the enormous population in the country and its limited transportation options. These issues could be attributed to the increasing urban populations and the incongruence with the geographic size of the country (Gorham 2017). The railroads in Nigeria are pre-colonial, and they are no longer function optimally (Okoye et al. 2019) while the new rail system is just currently under construction and could be ready until 2022 (PremiumTimes 2018). Lagos State Waterways Authority (LSWA), manages the Waterway, but the use of ferries and boats has not been well received as people feel it is not safe and does not serve most locations. Besides International Airways through Murtala Muhammed International Airport and Nnamdi Azikiwe International Airport, Abuja, road transportation is, however, the most dominant and most extensively used form of transportation in Nigeria (Nwafor and Onya 2019). It involves 
(1) the Lagos Bus Rapid Transit (BRT), regulated by the Lagos Metropolitan Area Transport Authority (LAMATA) and currently operated by Primero Transport Services Limited

(2) The Lagos Bus Services Limited (LBSL),

(3) Minibuses (locally called danfo), distinctly painted yellow and carries approximately $12-18$ passengers, and they are owned and operated by individuals (See Fig. 9.1),

(4) Taxis and Shared rides like Uber and Bolt

(5) Tricycles (locally called Keke) and

(6) Motorcycles (locally called Okada).

While there is government involvement in transportation services in developing countries, the ongoing dominance of small-scale, informal provision of transport services in most urban contexts has also been recognised (Gorham 2017). This ownership structure presents a significant implication on urban transport governance and responsibility for effectively managing the effect of this pandemic. This suggests that some of these small-scale individual owners may not be financially capable of providing measures to cope with the "new normal", which includes the provision of facemask, hand sanitisers and even social distancing. There are possibilities that they may decide to ignore the social distancing rule and carrying full passengers to keep making the profits they were making before the pandemic.

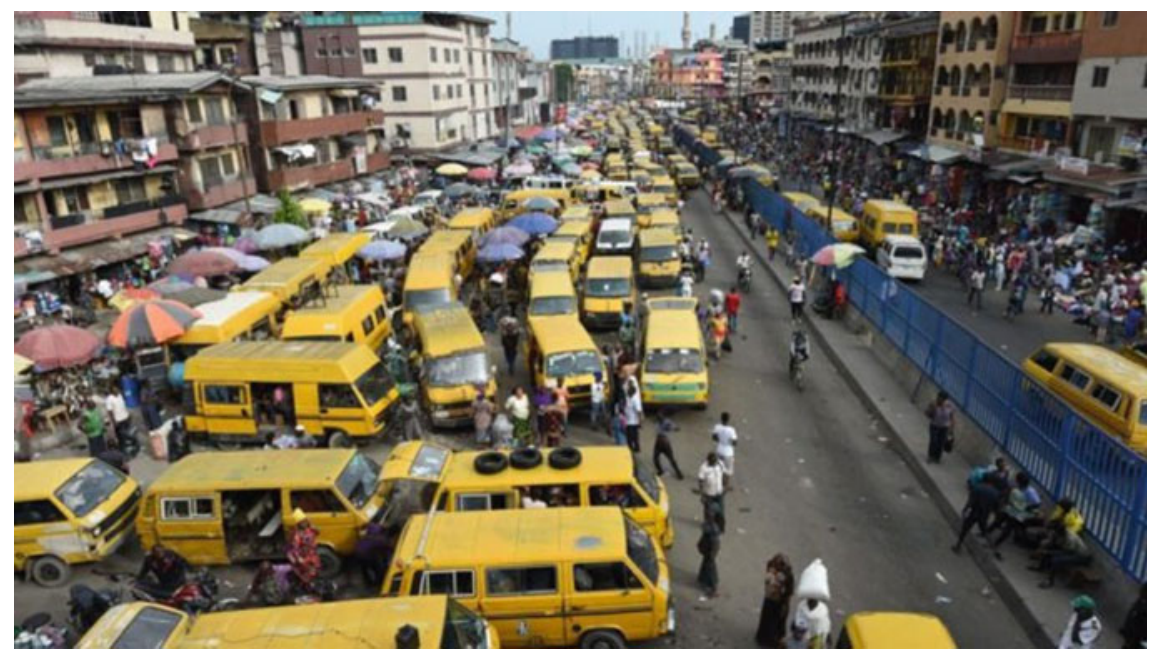

Fig. 9.1 Image of Minibuses (locally called danfo) in Lagos, Nigeria 


\subsection{Case Study Analysis of COVID-19 Induced Transport Service Delivery in Lagos, Nigeria}

In our case study analysis, we gauge the perceptions of individuals as to whether transport operators and commuters adhere to the social distancing directives while navigating their profit-seeking objectives and transportation demands, respectively. The instrument used as a barometer to generate credible inferences along the path of COVID-19-transportation dynamics in Lagos is presented below. We ask practical questions in our survey of around 334 commuters and transport operators in Lagos, Nigeria and obtained a response of 329 , which makes up $98.5 \%$ of our entire sample. Questions raised in the survey address the concern for safety, ease/ambiguity of navigating commuters transport demands, surge/fall in transport and desires for an alternative mode of transportation. Participants were also invited to provide thoughts on the impact of COVID-19 on transportation in the state. This submission provided additional qualitative data for the study.

\subsubsection{Quantitative Data Analysis and Result}

We obtained a $98.5 \%$ response rate, with about 329 samples correctly filled and returned. In other sections of the questionnaire, we analysed the demographic characteristics of the respondents. We predicted the post-pandemic changing nature of the transport service industry on observable changes in the transport demands of commuters and the associative fare prices hike at the time of COVID-19. In other climes, we analysed the expected income structure of the transport operators, which somehow determines a proportion of government revenue coming from ticket fees, taxes on transport facilities and so on. Our state-level analysis was based on questions addressing the core objectives of this study distributed along the Likert scale from one (1) to five (5). One (1) denotes no influence, two (2) represents a negligible influence, three (3) connotes indifference, four (4) indicates moderate influence and five (5) shows the significant influence of COVID-19 on transport demands of commuters, the profit-seeking objective of transport operators and welfare enhancement objectives of the government. With the global pandemic still in its active days and social distancing guidelines, the most pervasive option for reducing the spread of the virus, as well as restriction of movement and gathering in place in most cities across Nigeria, the convenience sampling technique became the most appropriate. The non-randomisation experimental approach of the convenience sample technique overrides other forms of data gathering procedures mainly as it allows for experimentation of a group of the respondent or individual respondent within reach. We accounted for outliers by expunging observations with sub-optimal information. We adopted the one-way analysis of variance (ANOVA) to predict the possibility of a significant difference in COVID-19 induced transport service delivery pre- and post-pandemic. 
In our baseline inferential statistical analysis, we reported various paths and dimensions to which COVID-19 influence the transport service delivery in Lagos, Nigeria. In Tables 9.1, 9.2, 9.3, 9.4, and 9.5, we showed the demographic characteristics of our dataset, including age composition of the respondent, categorisation of transport stakeholders, available transport modes, and the transport outlook in Lagos, Nigeria in the time of COVID-19.

Table 9.6 presents the result of the one-way analysis of variance test to gauge the possibility of a significant difference in COVID-19 induced transport service delivery during pre-pandemic and pandemic. The analysis of variance determines explicitly whether the differences between group means are statistically significant or not. We compared the $p$-value to the significance level to assess the null hypothesis. In these results, the null hypothesis states that COVID-19 influence on transport service delivery pre-pandemic does not significantly differ from COVID-19 influence on transport service delivery in the time of COVID-19 in the study area. Because the $p$-value of 0.000 was less than the significance level of $0.05(p<0.05)$, we reject the null hypothesis and conclude that COVID-19 influence on transport service delivery pre-pandemic significantly differs from COVID-19 influence on transport service delivery in the time of COVID-19 in the study area. The differences between condition means are likely due to chance and not likely due to manipulation.

This poor infrastructural development, high investment costs are ubiquitous challenges in developing countries alike (Gorham 2017) also presents another challenge for Nigeria. There is considerable reliance on the road, and another transportation option has not been well explored. The built environment has not supported walking, cycling, and other micro-mobility, which poses challenges for the country on how to deal with the impact of the pandemic on transportation.

While recognising these challenges, the subsequent section explores different measures that need to be put in place as commuters and transport providers operate post-pandemic. It is essential to understand that despite these challenges, measures have to be put in place to alleviate the impact of this pandemic both in the short- and long-term.

Table 9.1 Demographic characteristics of the dataset

Table 9.2 Age composition

\begin{tabular}{l|l|l}
\hline Gender & $N=329$ & Relative \% \\
\hline Male & 177 & 53.8 \\
\hline Female & 152 & 46.2 \\
\hline
\end{tabular}

Source Authors, 2020

\begin{tabular}{l|c|l}
\hline & & Relative \% \\
\hline $18-35$ years & 157 & 47.7 \\
\hline $36-50$ years & 129 & 39.2 \\
\hline 50 years and Above & 43 & 13.1 \\
\hline
\end{tabular}

Source Authors, 2020 
Table 9.3 Transport stakeholders categorisation

\begin{tabular}{l|r|c}
\hline & & Relative \% \\
\hline Workers on essential duties (Commuters and Cab Operators) & 91 & 27.7 \\
\hline Workers on non-essential Duties (Public) (Commuters and Cab Operators) & 22 & 6.7 \\
\hline Workers on non-essential duties (Private) (Commuters and Cab Operators) & 89 & 27.1 \\
\hline Self employed/business owners (Commuters and Cab Operators) & 103 & 31.3 \\
\hline Not employed (Commuters and Cab Operators) & 24 & 7.3 \\
\hline
\end{tabular}

Source Authors, 2020

Table 9.4 Transport modes in the time of COVID-19

\begin{tabular}{l|l|l}
\hline & & Relative \% \\
\hline Commercial vehicles/motorcycles & 172 & 52.3 \\
\hline Private vehicles/motorcycles & 147 & 44.7 \\
\hline Walking & 10 & 3.0 \\
\hline Cycling & - & - \\
\hline
\end{tabular}

Source Authors, 2020

Table 9.5 Lagos transport outlook in the time of COVID-19

\begin{tabular}{l|c|l}
\hline & & Relative \% \\
\hline Hike in fare price & 176 & 53.5 \\
\hline Inadequate fleet/excess transport demand & 72 & 21.9 \\
\hline Gridlock/congestion on major road network & 50 & 15.2 \\
\hline Adherence to social distancing guidelines & 31 & 9.4 \\
\hline
\end{tabular}

Source Authors, 2020

Table 9.6 One-Way Anova result

\begin{tabular}{l|l|l|l|l|l}
\hline & Sum of squares & Df & Mean square & $F$ & Sig \\
\hline Between group & 44.088 & 4 & 13.552 & 26.478 & 0.000 \\
\hline Within group & 175.462 & 324 & 0.511 & & \\
\hline Total & 219.550 & 328 & & & \\
\hline
\end{tabular}

Source Authors, 2020

\subsubsection{Qualitative Data Analysis and Result}

Two hundred seventy-one participants provided qualitative insights into how COVID19 has impacted their transport service experience. The comments were extracted from the Excel Spreadsheet and copied into Microsoft Word, where they were numbered and formatted. It was later imported into NVivo qualitative data analysis software program (Farinloye et al. 2019). Braun and Clarke's (2006) six phases of 
analysis were adopted for the analysis. The first phase is concerned with familiarisation with and immersion in the data, which involved reading the comments repeatedly to understand better how participants were engaging with transport services provision, the fears about travelling during the pandemic and measures they are putting in place to keep safe. From the familiarisation, initial codes were generated. These initial codes correspond to 'the most basic segment, or element, of the raw data or information that can be assessed in a meaningful way regarding the phenomenon' (Boyatzis 1998, p. 63). Third, subthemes (child nodes) related to the main themes (parent nodes) were identified. Fourth, the subthemes were reviewed and refined as it became evident that some of them were closely related. Fifth, when the refined child nodes were considered satisfactory, they were renamed to agree. Finally, the analysis identified three key themes that shape the commuters' experience of transport services.

\subsubsection{Government Involvement}

The participants had an expectation from their government with regards to transportation services. They expected the government to provide solutions to their travel troubles through reducing transportation fees, removing the transport restrictions and importantly, improving the transport infrastructures.

The government should have a say on the transportation fee because it is extremely high. I have my car, which I started frequently using now because of COVID, but notwithstanding traffic is something else. Govt, please look into it.

Our government needs to come up with practically workable guidelines that would both place operators and commuters in an advantage position economically and public health-wise so that at the end of the day, it would be a win-win scenario for both parties.

The government should totally ease the lockdown and open the economy so that everything can get back as normal. Let the transporters stop taking advantage of any situation to hike prices.

The participants reported that the pandemic has put huge pressure on existing inefficient transportation in Lagos State and further suggested that a mega city like Lagos should have a more developed transportation system that can cope with the pandemic and any other emergencies.

The government needs to provide better public transportation. Everyone can see that we are not ready to be a megacity. The impact of Covid19 on transportation, like almost every other sector, is adverse. There is a great need to evaluate the current approach.

Bad impact. First, the high cost of transport. Second, scarce transport.

It has exacerbated the mayhem commuters are often subjected to as a result of heavy traffic congestion on the highway. 


\subsubsection{Business Operation of Service Providers}

Moving on from the demands from the government, commuters also recognised the role of the services providers and the impact of their business operations. Participants noted that even with the social distancing in place, they do not feel safe using public transportation as the drivers are not putting measures in places to protect them

There is no social spacing at all; we were all rushing to get the bus. You would expect the bus owners to take some responsibility, but it seems no one cares. You must take care of yourself. No social spacing on these buses.

Social distancing not observed, terrible hiking of transportation

Although fares have been hiked, commuter buses are still conveying passengers at full capacity. Also, for a fast-paced city like Lagos, where the use of "Okada" is the "norm", suspension of commercial motorcycle operators has put a strain on public commute.

There were also concerns around the cost of transportation, these confirmed findings from the quantitative studies, commuters further noted that the transportation prices had been shifted to the passengers.

The impact of COVID-19 on transportation in Lagos is severe. The cost of transportation has gone up due to the fact that the number of passengers carried by the transport vehicles has reduced and the passengers are made to pay more to augment it. Also, there is a shortage of transport vehicles because some drivers are scared of the COVID-19 and will prefer to use their buses for other purposes rather than for transportation services.

Less buses and high fares. BRT provided by the government also not available most times.

Base on the times that I have been out, due to the reduction of numbers of passengers in tricycles from three to two transports has been double.

\subsubsection{Call for Regulation}

As commuters complained about their experiences on public transportation, the lack of protection and organisation, there were concerns about the need for the transportation industry to be regulated. It is important to note that there are many stakeholders in this sector, as there are the individual self-employed drivers, there are the Okada riders and the government owners.

Transportation in Lagos is so disorganised and no wonder it cannot be monitored. It is time for the government to structure the sector, make them accountable, and make people feel safe. They cannot just be increasing transport fare, flaunting social distancing spaces and nothing will happen to them.

In line with the demand for regulation, there are demands for private transportation, which can be well managed and safe. People feel that there is a need for more private investment, recognising the huge population of the state, there is a big market

We can see that transportation in Lagos is not right at all, and I think there is an opportunity for private investors. Somebody who can invest in boat transportation and do something different. 
Cheaper and faster means of transportation will be truly welcome in Lagos.

While we wait for the government to invest in transportation, the private investor might come in to save us. They have banned Okada, but I think there are other business opportunities for transportation service in the state.

\subsection{Enhancing Transport Service Experience}

This unprecedented time calls for unprecedented action to protect the safety, security and health of transport workers and commuters. This chapter focusses on dealing with the impact of COVID-19 pandemic on transportation services in developing countries. The results indicates commuters concern about the hike in the price of transportation, the inadequate fleet of transportation, which is not meeting the transport demand, the traffic congestion and lack of adherence to social distancing guidelines. There are implications for transport service providers to redesign their offering and the government to provide an enabling environment.

This section serves as the discussion of the result of the case study. It highlights key measures and recommendations, based on customers' insight that emerges from the survey and subsequent analysis and examples from developed countries, to highlight what has been done and what can be achieved in many of the developing countries. These action plans are presented in recognition of customers' need and desire to have a good experience using the transport services.

\subsubsection{Customer Engagement}

There is a paradigm shift, and customers are more aware and cautious of their health and safety as they use transportation. Therefore, service providers need to engage with customers concerning different actives and measures in place to ensure their safety. There is a massive responsibility of the service providers to recognise the impact this pandemic has had and will have on service provision and, therefore, effectively communicate with customers and all stakeholders. Efforts should be put towards improving customer services, engagement, and communications, and Service providers need to reassure their customers that their wellbeing is important, communicating the changes and adjustments with the customers. New York's Metropolitan Transportation Authority (MTA) has launched a new "Keep them Covered" public awareness campaign to wear a face-covering while riding public transportation (MTA 2020). The new campaign includes digital signage across more than 7000 digital screens, audio announcements in stations and on trains, and more than 7000 printed signs for buses and paratransit vehicles. Service providers can use social media for customer engagement and communication, updating their websites 
for relevant information and use various media to engage with the customers (Gökerik et al. 2018; Mogaji et al. 2020).

\subsubsection{Service Design}

\subsubsection{Protection of Staff and Commuters}

In coping with the new normal, masks, gloves and sanitisers are the new reality of public transportation. Passengers on public transport and stations are expected to wear face coverings in all situations where the social distance rules cannot be maintained. In some countries in the developed world, wearing a mask is being made compulsory. The service design recognises the need to make these protective wears available for staff and commuters. In Moscow Metro stations, protective masks and gloves can be purchased at vending machines and stations' retail outlets. While, in some cases, these masks are provided free of charge, it is crucial to consider the modalities in emerging countries where the provision of the masks may not be financially sustainable in the long run. The affordability and provision can become an issue in developing countries. Service providers may want to consider making this available for customers, provided it is economically viable. Likewise, hand sanitisers will be needed as we move on post-pandemic. These masks and hand gel could be provided by the transport owners to ensure the safety of those using their transportation mode.

\subsubsection{Protecting Share Rides}

Moving beyond public mass transport, there are also concerns for protecting share rides and taxis, taking into consideration they have an increased risk of acquiring the virus, given their close contact with their customers (Yezli and Khan 2020), it is essential to put measures in places that these self-employed individuals are taking responsibilities to protect themselves and their customers. As seen with Lyft, rideshare company, they have made face masks mandatory for their rides, an effort to protect riders and drivers. The rideshare company recently announced a Health Safety Program with new policies, commitments, and products designed to address the needs of our community during this critical time for public health (Lyft 2020). As a matter of changes to the design of the mode of transportation, drivers will have to be partitioned and protected. This, however, provided a different challenge for developing countries where they use different types of transportation modes, which may not make social distancing feasible. There are motorcycles and tricycles where there are close contacts with the riders. The protection of the driver may not be possible; therefore, using a nose mask may be a better alternative. 


\subsubsection{Temperature Scanners}

In addition, to service design, there will need to install temperature scanners at terminals and airports to check the temperature of people before boarding. Singapore's Land Transport Authority (LTA) installed thermal scanners at selected stations to provide an additional layer of screening before commuters enter the public transport network. Passengers who have been picked up by the scanners as having a fever will not be allowed to enter the station and be asked to seek medical attention at the nearest clinic(s) immediately. For a start, these thermal scanners have been deployed at Serangoon and Tiong Bahru MRT stations. Other types of surveillance using Artificial Intelligence (AI) are also possible. Kogniz has created a thermal security platform that uses AI to track fevers from a distance, identify exposure risks, and enforce social distancing and protective.

\subsubsection{Social Distancing Markers}

There are physical infrastructural changes that need to be made as transport service providers and commuters cope with the new normal, among which are the social distancing marking to encourage people to leave the required distance between themselves even though they must use public transport. Singapore's Land Transport Authority (LTA) requires all trains and train stations, as well as buses, bus interchanges, and bus stops to be marked with safe distancing stickers. Markings on the footpath, intersections, and at the bus stop to support physical distancing are also encouraged. Controlling the crowd and the insufficient transports infrastructures in these developing countries possess a challenge in implementing this. While commuters are expected to adhere to the spaces that are demarcated, to maintain safe distances from others when commuting, it is essential to have measures in place to enforce this social distancing. The service providers need to put policies and measures in place to support their staff to implement this spacing. Drones for communication, enforcing social distancing rules, and delivery of essential goods like foods and medical supplies. As social distancing will reduce the number of spaces on available fleets, there is a need to increase the number of fleets to meet the growing demands.

\subsubsection{Co-creating Timetable and Schedule}

The transport services need to be redesigned to meet the changing needs of the commuters and also the social distancing policy as long as it is in place (Mogaji 2020). The infrastructural redesign is necessary as part of the measures to enhance the customer service experience. Both the service providers and the government are responsible for the redesign. However, there are possibilities for co-creating the service with the customers. Transport service providers should endeavour to cocreating the new scheduling and timetabling arrangement. The service providers 
need to know the travel behaviour as a pattern of the commuters, especially post lockdown, when there could be reduced motivation to travel. The bus that was previously serving 20 people may have to help ten people now, and there are bound to be some inconveniences, scheduling and timetabling will go a long way in easing the pressure. For example, as a way of improving transport networks as a result of COVID-19, Oxford Council reorganised bus routes and timetables to create additional spaces and frequent services. This could also become relevant if there is a need to limit the number of commuters who can enter train stations, ferry terminals, and bus stops.

\subsubsection{Service System and Process}

\subsubsection{Infrastructural Development}

Government support in enhancing service delivery cannot be overemphasised. However, there are economic challenges in developing countries, and the government will have to bear some responsibilities, either through subsiding the transportation, providing loans and grants to those who want to change their fleets, providing cleaning materials and PPE for drivers and commuters. Oxford Council in the United Kingdom had to temporarily reallocate road to allow people to walk and cycle safely, and this was achieved through road closures, traffic light controlled one-way streets, and broader pavements, segregating network of cycle routes and improving cycling infrastructure like on-street cycle parking. France has announced a scheme to encourage people to cycle more. London had to ban cars from certain roads to reduce the overcrowded pavements and make our daily exercise more accessible and safer. Likewise, Paris had some its streets closed to vehicles after the lockdown and turned into cycle highways, Auckland Transport announces changes to a significant road to increase space for those walking, on bikes and more area at intersections and crossing to reduce crowding and give people space to cross. These examples around the world highlight how the government has worked with transport service providers to ease the journey and allow other modes of transportation. It is, however, necessary to recognise the challenges with developing countries where there are limited existing infrastructure, urban plans and layout has not been designed to accommodate the changes and likewise the economic implication of making these changes, notwithstanding, it is essential to plan for the future, deigning dedicated cycling lane to encourage people to cycle across the cities safely.

\subsubsection{Contactless and Mobile Payment}

In addition to physical modifications done to service delivery, service providers in developing countries may want to adopt technology and integrate contactless and other mobile payment platforms. While this is prevalent in ride-hailing platforms 
like Uber and Taxify, other transport service providers may want to explore this cashless payment as they revamp their service system and process. Mogaji (2020) noted that cash payment is predominant on Lagos transport, and this puts drivers and essential workers at a higher risk of spreading the virus.

\subsubsection{Regular Cleaning and Disinfection}

Regular cleaning and disinfection of transport and transport hubs will be an integral part of the service design to reduce the spread of the virus. To increase the protection of taxi drivers and protect them and their passengers from the coronavirus, Dubai's Road and Transport Authority (RTA) has provided a self-sterilisation booth to sterilise taxis, drivers, clothes and shoes as soon as they finish work. The selfsterilisation corridor sprays disinfectant around the body circumference (Oommen 2020). Madrid has made a 9000-square-metres space available for local taxi drivers to clean and disinfect their automobiles for free (Dimitrova 2020). On a long-term plan, transportations service providers may have to consider installing medical-grade air cleaning systems in their cabins to reduce the spread of the virus, which is airborne, possibly. Also, surfaces will have to be protected with long-lasting coasting on materials that will not support the spread of the virus.

\subsubsection{Evaluation of Service System and Process}

As part of the service design, it is essential to evaluate different measures that are in place continually. As commuters and transport service providers engage in the new normal, there are possibilities that some of the measures put in place may not be adhered to. Service providers need to be sure that their staff are not lackadaisical, policies, procedures and guidelines that have been put in place should be strictly adhered to. The government may also have to come on board in a situation where the service provider may not want to respect the social distancing.

\subsubsection{Newly Emerging Product-Service Systems}

\subsubsection{Technology in Service Redesign}

Technology will play a crucial role in the redesigned service delivery. EnelX, the innovative global business line of the Enel Group, and HERE Technologies, a global leader in geographical data and mapping services, launched "City AnalyticsMobility Map" which provides Italian government agencies with mobility indicators to support in the COVID-19 emergency (EnelX 2020). The big-data solution estimates variations in the public's movements and kilometres travelled throughout national, regional and municipal areas in Italy. Customers' engagement with different 
touchpoints can be evaluated to have a better understanding of travel behaviours and service consumption. The technology can also be used to support customer engagement and interaction. AI and data analytics will also become relevant in understanding the consumers' behaviours and changing the services to meet their needs (Dwivedi 2019). AI can be used to identify areas that need more support. There are possibilities for improving service delivery through improvement through digital assistants to meet better the increasing demand and dynamic environmental changes (Schweiger 2020). This digital assistant could be used to substitute for human contact regarding purchasing fare products and supporting less abled commuters (Schweiger 2020).

\subsubsection{Alternative Transport Mode}

As the world copes with the new normal, it is essential to adjust the physical planning of the environment to encourage other forms of transportation beyond just road. There are huge opportunities to provide train transport services, waterway way transport services, and even cable cars. These, however, will hugely rely on government investments in infrastructure and policies to support private investors.

Other means of transportation for those who may not want to use public transport are also possible. David Spielfogel, Lime Chief Policy Officer, described the postCOVID world as the micro mobility's moment (Spielfogel 2020). Lime Bike has also made plans to reactivate small fleets of scooters to meet the growing demand for micro-mobility. Micro mobility devices, including bicycles, Ebikes, electric scooters, electric skateboards, shared bikes, and electric pedal-assisted (pedelec) bicycles, should become an integral part of transportation mode in the post-COVID world. They, however, need to be supported by infrastructural changes to the built environment (Farinloye et al. 2019). The environmental benefits of these additional modes of transportation also need to be considered as more justification for its inclusion. Besides, it opens opportunities for emerging service system for those who are looking for alternative means of transportation.

\subsubsection{Freight and Cargo Transportation}

As public transportation may be significantly hit and slowly recover from the impact of the pandemics, freight and cargo transport may need to be redesigned to meet the growing needs. Commercial truck drivers were exempt from the non-essential business closures and stay-at-home orders implemented by most countries, and this may make many other transport service providers may have to explore this option to remain commercially viable. This could also include exploring railways, which can enhance export markets through coastal ports (Okoye et al. 2019), with little reliance on on-road transportation. 


\subsubsection{Autonomous Vehicles}

As people want to avoid contact on public transportation, there is the possibility of an increase in the development and use of autonomous vehicles (AVs) as people will want to avoid contact. Rather than public transport services being operated by humans, robots, who are susceptible to disease and infection, may be responsible for public transport services. While this may not be an immediate agenda for developing countries with more pressing it, it is presented as a plan worth exploring.

\subsection{Conclusion}

Transportation plays a significant role in the life and the development of a nation. Indeed, several authors both practitioners, professionals and those in academia have all accepted the fact that the life of a nation depends on its transportation systems, not only because it plays an increasingly important part in the nation's daily activities but also of its role in socio-economic and political development of the nation. However, in many developing countries, including the knowledge of the ways and means in which transport can best be planned to fulfil its central role is still very limited. The arrival of COVID-19 makes the understanding of transport infrastructure development even more imperative as commuters, operators and government device new means to navigate their transport demands, profit seeking objectives and revenue generation processes respectivley.

Without doubt, there is a wide gap between the assumed role of transportation in the development of the countries and the extent to which in practice the development of transport can be put into effective use for the development of this nation more pressingly in the time of COVID-19. The social distancing guidelines and practice of good hygience to abate the spread of the virus has intensify the need to redesign and reframe existing transport modalities and functions to suit all and sundry. It is in relation to these that this chapter is written. In other words, this chapter brings into contemporary focus a detailed account of COVID-19 has impacted transportation, transportation service and logistics in Lagos, Nigeria and highlights through some suggestions on how best the transportation systems and physical distribution of goods and services can best be improved in the time of COVID-19 and the post pandemic. It brings into focus the basic principles of how alternative transportation modes can be explored to reduce the pressure on popular road network and highlights their characteristics and the extent to which they have been valuable and could be valuable to the long term development of the country during the pandemic and post pandemic.

This chapter recognises that COVID-19 will change the provision and delivery of transportation services, especially in developing countries with existing underlying economic challenges, weak transportation infrastructures and growing population. While it is still uncertain how the pandemic will eventually end, we will see prolonged effects from COVID-19 on all areas of human activities. 
This chapter has identified implications for transport workers whose role may be changing as the consumer shift their behaviours and technology become more relevant. There is going to be less interaction due to demarcations that have been installed, a mobile application providing direction and autonomous driving. The changing commuters' behaviour is also recognised-wearing personal protective equipment like a face mask and using hand gel, social distancing, going through temperature scanners and using an alternative mode of transportation like walking or cycling. The role of technology and data analytics in shaping transportation services while recognising the limitations with devices and internet connections have also been discussed in how to cope with the new normal.

This chapter makes key theoretical contributions. First, it contributes to the emerging literature on the impact of the pandemic on developing countries (Adekunle et al. 2020; Mogaji 2020). Second, it provides theoretical insight into service provision post-pandemic, highlighting how the transport service will change as it meets the changing demands of customers. The pandemic is a global problem, and a holistic understanding is needed. Third, the chapter focuses explicitly on transportation services in developing countries. It recognises the opportunities and inherent challenges for services providers, service design and service quality and improvement (Caro and García 2007; Mogaji and Erkan 2019). Four, this chapter contributes towards a study on transportation, travel behaviour and the built environment. It recognises the impact of poor infrastructure on transportation and ardently on transport services provision and service system and process.

Managerial implications for government, policymakers and transport services providers were also provided. Developing countries have their challenges, but notwithstanding, they need to plan and adjust for what lies ahead as stakeholders navigate this precarious time and chart a new path for individuals and many other developing countries. Short-term and long-term plans have been identified in coping with the new normal and enhancing customer experience management. The government has a responsibility to provide the infrastructure that can support transport service delivery while policymakers need to provide an enabling environment for the service providers and prospective investors. Services providers also need to redesign and co-create value in their services in recognition of an immediate transition of service processes (Grönroos 2011), effectively communicate and engage with the customer through social media and other platforms (Mogaji and Erkan 2019) and ensure technology-enabled customer encounters (Lee and Lee 2020). The service provision landscape is changing to align with customers' expectations. The role of technology as part of infrastructural changes to enhance customer experience management cannot be overemphasised. There are huge possibilities for smart service innovation in the developing countries where information about travel patterns and customer engagement can be used to ethically collected, opportunities for cashless payment and enhance customer engagement with services providers through chatbots and virtual assistants.

This chapter has some limitations, which we hope future studies will address them. Participants were recruited from Lagos Nigeria, a state with a population of over 20 million people. Therefore, the number of participants in this study is not 
a representative sample. Likewise, the data collected may not represent the travel behaviour, impact, and experiences of commuters in Nigeria or other developing countries. Future studies may want to explore the impact of COVID-19 on services provision using a larger sample and to replicate the study in many other developing countries

The qualitative insight from this study was based on the open-ended questions that commuters' answers during the survey, future studies may want to carry out proper interviews with commuters to generate qualitative data which will provide more insight into the experience of transport services. Besides, services providers were not surveyed as part of this research due to the time constraints and logistics in reaching out to the future research should endeavour to surveyed service providers to understand how their service delivery has changed, their value co-creation process and measure put in place to ensure customer satisfaction and safety. Likewise, future research can engage with policymakers and government officials to understand their responsibility to enhance transport service delivery and commuters' experience.

\section{Appendix}

\section{SUMMARY OF THE QUESTIONNAIRE}

Are you resident and presently in Lagos at the time of filling this questionnaire?

[] Yes

[] No

What is your usual mode of transportation in Lagos?

[ ] Public Transport

[ ] Private Car/Motorcycle

[ ] Walking

[] Cycling

From your experience, what has been the major impact of COVID-19 on Transportation in Lagos?

[ ] Cost of Transportation

[ ] Shortage/lack of Transportation mode

[ ] Traffic congestion

[] Social distancing

What is your usual mode of PUBLIC transportation in Lagos?

[ ] BRT

[ ] Danfo

[ ] UBER/Taxi

[ ] Keke/Tricycle

[ ] Okada (Motorcycle)

[ ] Ferry

[ ] Train

Since the outbreak of COVID-19, have you experienced a rise in the cost of transportation? Has transportation become more expensive? 


\section{[] Yes}

[] No

How has the coronavirus impacted your transportation within Lagos?

[ ] 1-No impact

[ ] 2-Minor impact

[ ] 3-Neutral

[ ] 4-Moderate impact

[ ] 5-Major impact

How has the coronavirus impacted your economic activities?

[ ] 1-No impact

[ ] 2-Minor impact

[ ] 3-Neutral

[ ] 4-Moderate impact

[ ] 5-Major impact

How has the coronavirus impacted your social activities (visiting friends, attending parties, going clubbing)?

[ ] 1-No impact

[ ] 2-Minor impact

[ ] 3-Neutral

[ ] 4-Moderate impact

[ ] 5-Major impact

How has the coronavirus impacted your religious activities? (going to church, going to the mosque, Easter or Ramadan).

[ ] 1-No impact

[ ] 2-Minor impact

[ ] 3-Neutral

[ ] 4-Moderate impact

[ ] 5-Major impact

How likely are you to keep observing the lockdown?

[ ] 1-Extremely unlikely

[ ] 2-unlikely

[ ] 3-Neutral

[ ] 4-likely

[ ] 5-Extremely likely

How likely are you to consider alternative travel mode?

[ ] 1-Extremely unlikely

[ ] 2-unlikely

[ ] 3-Neutral

[ ] 4-likely

[ ] 5-Extremely likely

How likely are you to use a Bicycle or walk?

[ ] 1-Extremely unlikely

[ ] 2-unlikely

[ ] 3-Neutral

[ ] 4-likely 


\section{[ ] 5-Extremely likely}

What Local Government Area do you reside?

What is your Employment status?

[ ] Essential Worker (Nurses, Doctors, Food seller)

[ ] Non-Essential Worker (Public)

[ ] Non-Essential Worker (Private)

[ ] Self Employed/Business Owners

[ ] Not Employed.

What is your Age group?

[ ] 18-35

[ ] 36-50

[ ] 50 above

Gender

[ ] Female

[ ] Male

Open-Ended Question: Any closing thoughts, experience or description of transport services in the state?

\section{Author's Insight}

Transportation is essential to the economy since it aids the mobility of human, goods and services. Despite its established importance, there is little infrastructural investment from the government in developing countries to meet rising transportation demands of its populace. Underdeveloped and unexplored alternative transportation modes relative to the road transportation options have kept enormous pressure on the existing road networks and facilities leading to traffic congestion, pollution, accident and more significant concerns of public health deterioration.

The arrival of COVID-19 has exposed further the inadequacies of our transport infrastructure development strategies. The novel diseases transmitted from humanto-human has forced upon us new ways of navigating our transportation demands and how transport operators and government can meet up the rising transportation needs of the people. The challenges of transport service and delivery are forcing us to devise better ways of enhancing our transportation system. From the commuters who are conscious of their safety in commercial transit and rise in transport fare, to operators who are concerned about the return on their transport investment, and also the government who are equally worried about revenue generation from tickets, taxes, the rising cost of road maintenance. As we begin to see more people travel in personal vehicles to reduce contact in the time of COVID-19, the dimensional changes to transport service and delivery during and after the pandemic is a challenging but also an exciting discourse that needs to be framed appropriately for policy and research.

Notwithstanding these challenges, the transportation services are being redesigned, and there are new behaviours that are becoming part of the new normal. 
To further enhance this experience, the role of government cannot be overemphasised. While the government may increase their effort towards improving facilities and providing infrastructures, we envisage a delay in the timeline, this, however, will spur digital innovations as commuters, and other stakeholders look for alternative solutions to ease their transportation problems. Policy measures to support this innovation is nonetheless essential.

The service redesign needs to consider the policies of the government, so as not to invest where there is no priority by the government. There will be more investment in private transport mode, starting with road transportation with more conducive albeit expensive but private executive transportation for members of the public. There will be more investment in the waterways, encouraging more passengers to use ferry and boats to access cities (in our case study experience, rise in Ferry usage has begun within Lagos during the time of COVID-19). Train transportation, albeit maybe complicated to innovate considering its huge investment. Again, government support is essential to make this work.

For self-employed service providers, it is projected that they will find alternatives to keep themselves viable, possible they will not adhere to social distancing, or there will be an increase in price as their business operation changes and they want to remain commercially viable. It is, however, essential for commuters to change their travel behaviour. This change could either mean working more from home to avoid travel or using alternative means like walking. Many may now want to consider buying a car because it can be regarded as safer, there are however implications on transport congestion as there are more vehicles on the road. Cycling could be an alternative approach, but it may be challenging to integrate into the urban layout of a state like Lagos, perhaps this is a long-term investment, again on the part of the government.

We also projected more improved transport services, where all stakeholders are known, engaged ad monitored. The transport routes are documents, easy to carry out tracing and importantly adopting technology to ease the service provision. The tech companies may take the driving seat in the discussion for a more regulated industry, but the reluctance of the government, policymakers and other groups with a vested interest may not make this achieved quickly. Transport service will change post-pandemic, the government has to support the services providers because they have a crucial role in having a role to play in ensuring the customer's experiences are positively enhanced.

\section{References}

Adekunle, I. A., Onanuga, A., Wahab, O., \& Akinola, O. O. (2020). Modelling spatial variations of coronavirus disease (COVID-19) in Africa. Science of the Total Environment, 729, 138998.

Boyatzis, R. E. (1998). Transforming qualitative information: Thematic analysis and code development. Sage: London.

Braun, V., \& Clarke, V. (2006). Using thematic analysis in psychology. Qualitative Research in Psychology, 3(2), 77-101. 
Caro, L. M., \& García, J. A. (2007). Measuring perceived service quality in urgent transport service. Journal of Retailing and Consumer Services, 14(1), 60-72.

Dimitrova, A. (2020). Madrid offers free disinfection of taxis. Retrieved May 5, 2020, from https:// www.themayor.eu/en/madrid-offers-free-disinfection-of-taxis.

Dwivedi, Y. (2019). Artificial Intelligence (AI): Multidisciplinary perspectives on emerging challenges, opportunities, and agenda for research, practice and policy. International Journal of Information Management. https://doi.org/10.1016/j.ijinfomgt.2019.08.002.

EnelX. (2020). Retrieved May 5, 2020, from https://www.enelx.com/en/news-and-media/press/ 2020/04/enel-x-and-here-technologies-launch-city-analytics-mobility-map-to-support-govern ment-agencies-and-the-civil-protection-department-in-response-to-the-covid-19-emergency.

Farinloye, T., Mogaji, E., Aririguzoh, S., \& Kieu, T. (2019). Qualitatively exploring the effect of change in the residential environment on travel behaviour. Travel behaviour and society, 17, $26-35$.

Gökerik, M., Gürbüz, A., Erkan, I., Mogaji, E., \& Sap, S. (2018). Surprise me with your ads! The impacts of guerrilla marketing in social media on brand image. Asia Pacific Journal of Marketing and Logistics, 30(5), 1222-1238.

Gorham, R. (2017). Nigeria. In D. Pojani \& D. Stead (Eds.), The urban transport crisis in emerging economies: The urban book series. Cham: Springer.

Grönroos, C. (2011). Value co-creation in service logic: A critical analysis. Marketing Theory, 11(3), 279-301.

Lee, S. M., \& Lee, D. (2020). "Untact": A new customer service strategy in the digital age. Service Business, 14(1), 1-22.

Lyft. (2020). Lyft launching personal health certification, will require face masks as part of new Health Safety Program. Retrieved May 10, 2020, from https://www.lyft.com/blog/posts/lyft-lau nching-health-safety-program.

Mogaji, E. (2020, July). Impact of COVID-19 on transportation in Lagos, Nigeria. Transportation Research Interdisciplinary Perspectives, 6, 100154.

Mogaji, E., \& Erkan, I. (2019). Insight into consumer experience on UK train transportation services. Travel Behaviour and Society, 14, 21-33.

Mogaji, E., Balakrishnan, J., \& Kieu, T. A. (2020). Examining consumer behaviour in the UK Energy sector through the sentimental and thematic analysis of tweets. Journal of Consumer Behaviour. https://doi.org/10.1002/cb.1820.

MTA. (2020). MTA launches 'keep them covered' campaign as New Yorkers now required to wear face coverings while riding public transportation. Retrieved May 5, 2020, from http://www.mta.info/press-release/mta-headquarters/mta-launches-\%E2\%80\%98k eep-them-covered\%E2\%80\%99-campaign-new-yorkers-now-required.

NNPC. (2020). Production. Retrieved April 4, 2020, from https://www.nnpcgroup.com/NNPC-Bus iness/Upstream-Ventures/Pages/Oil-Production.aspx.

Nwafor, M., \& Onya, O. (2019). Road transportation service in Nigeria: Problems and prospects. Advance Journal of Economics and Marketing Research, 4(3), 104-117.

Obi, D. (2018). Lagos commuters lose $75 \%$ of weekly working hours to traffic. Retrieved April 4, 2020, from https://businessday.ng/uncategorized/article/lagos-commuters-lose-75-of-weeklyworking-hours-to-traffic/.

Okoye, D., Pongou, R., \& Yokossi, T. (2019). New technology, better economy? The heterogeneous impact of colonial railroads in Nigeria. Journal of Development Economics, 140, 320-354.

Oommen, A. (2020). Dubai Taxi launches self-sanitisation booth for taxi drivers. Retrieved May 5, 2020, from https://www.constructionweekonline.com/products-and-services/264781-videodubai-taxi-launches-self-sanitisation-booth-for-taxi-drivers.

Pojani, D., \& Stead, D. (2017). The urban transport crisis in emerging economies. Cham, Switzerland: Springer.

PremiumTimes. (2018). Lagos light rail to commence operation 2022-Official. Retrieved July 7, 2020, from https://www.premiumtimesng.com/regional/ssouth-west/279888-lagos-light-rail-tocommence-operation-2022-official.html. 
Schweiger, C. (2020). How has COVID-19 impacted 2020's mobility trends? Retrieved May 5, 2020, from https://www.intelligenttransport.com/transport-articles/98257/how-has-covid-19impacted-2020s-mobility-trends/.

Spielfogel, D. (2020). Supporting Transit, people, and cities through challenging times. Retrieved May 5, 2020, from https://www.li.me/second-street/supporting-transit-people-and-cit ies-through-challenging-times.

Yezli, S., \& Khan, A. (2020). COVID-19 social distancing in the Kingdom of Saudi Arabia: Bold measures in the face of political, economic, social and religious challenges. Travel Medicine and Infectious Disease, 101692.

Dr. Emmanuel Mogaji is a Senior Lecturer in the Department of Marketing, Events and Tourism at the University of Greenwich. His research interests are in service brand management, service technology and travel behaviour. He published peer-reviewed journal articles and book chapters and presented his works in many national and international conferences. His publications have appeared in Journal of Product and Brand Management, Australasian Marketing Journal, Transport Behaviour and Society and Transportation Research Interdisciplinary Perspectives

Ibrahim Ayoade Adekunle is a Ph.D. Candidate at the Department of Economics, Olabisi Onabanjo University and also a Research Fellow at the European Xtramile Centre of African Studies, Liège, Belgium. He has B.Sc. Economics (Ed) from Tai Solarin University of Education, MSc from Nigeria's highly prestigious University of Lagos. His research interest are in Development Economics, Welfare Economics and Finance and Public Sector Economics. He has a considerable numbers of his papers published in Journals indexed in Web of Science and Scopus indexed academic outlets.

Dr. Nguyen Phong Nguyen is a Vice Head of Department of Research Administration and International Relations, University of Economics Ho Chi Minh City, Ho Chi Minh City, Vietnam. Dr. Nguyen is also a member of Certified Practising Accountants, Australia. His research focuses on coopetition, mindfulness, and branding. His publications have appeared in Industrial Marketing Management, European Journal of Marketing, Public Management Review, Journal of Product and Brand Management, Asia Pacific Business Review, and Australasian Marketing Journal.

Open Access This chapter is licensed under the terms of the Creative Commons AttributionNonCommercial-NoDerivatives 4.0 International License (http://creativecommons.org/licenses/bync-nd/4.0/), which permits any noncommercial use, sharing, distribution and reproduction in any medium or format, as long as you give appropriate credit to the original author(s) and the source, provide a link to the Creative Commons licence and indicate if you modified the licensed material. You do not have permission under this licence to share adapted material derived from this chapter or parts of it.

The images or other third party material in this chapter are included in the chapter's Creative Commons licence, unless indicated otherwise in a credit line to the material. If material is not included in the chapter's Creative Commons licence and your intended use is not permitted by statutory regulation or exceeds the permitted use, you will need to obtain permission directly from the copyright holder.

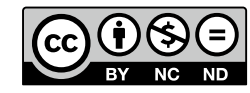

